\title{
A INFLUÊNCIA DAS PRÁTICAS DE GESTÃo DE PESSOAS SOBRE A ROTATIVIDADE DE PESSOAL
}

THE INFLUENCE OF MANAGEMENT PRACTICES OF PEOPLE ABOUT THE TURNOVER

Recebido em 26.01.2020 Aprovado em 09.03.2020

Avaliado pelo sistema double blind review

DOI: https://doi.org/10.32888/cge.v8i1.40540

\author{
Gabriel Resende Costa \\ gabriel.resende2009@gmail.com \\ Pontifícia Universidade Católica de Minas Gerais (PUC Minas) - Belo Horizonte/MG, Brasil \\ https://orcid.org/0000-0001-9416-5049 \\ Júlio Fernando da Silva \\ juliofs02@hotmail.com \\ Pontifícia Universidade Católica de Minas Gerais (PUC Minas) - Belo Horizonte/MG, Brasil \\ https://orcid.org/0000-0002-8367-6537
}

\section{Resumo}

Este estudo tem por objetivo compreender a influência das políticas e práticas de gestão de pessoas na rotatividade de pessoal em uma pequena empresa do comércio varejista de produtos alimentícios na cidade de Belo Horizonte - MG. Para isso, realizou-se um estudo de caso por meio da pesquisa documental, observação e entrevistas realizadas com os colaboradores da organização. Concluiu-se uma forte influência das políticas e práticas de gestão de pessoas na rotatividade de pessoal na organização devido, principalmente, a criação do documento "Política de Recursos Humanos" e uma pequena redução no número de admissões e demissões, como consequência de sua implementação. Assim, é notório que as taxas de rotatividade sofrem consequências diretas das ações de gestão de pessoas adotadas pelas organizações. Como contribuição, ratifica-se a importância do investimento em práticas de gestão de pessoas alinhadas a estratégias organizacionais e ao bem-estar dos trabalhadores, o que resulta na retenção e satisfação das pessoas e, consequentemente, na sustentabilidade dos negócios.

Palavras-chaves: Gestão de Pessoas. Políticas e Práticas de RH. Rotatividade de Pessoal.

\begin{abstract}
This study aims to understand the influence of people management policies and practices on staff turnover in a small food retailer in the city of Belo Horizonte - MG. For this, a case study was conducted through documentary research, observation and interviews with the employees of the organization. A strong influence of people management policies and practices on staff turnover in the organization was concluded, mainly due to the creation of the document "Human Resources Policy" and a small reduction in the number of hires and dismissals as a consequence of its implementation. . Thus, it is clear that turnover rates suffer direct consequences of the people management actions adopted by organizations. As a contribution, the importance of investing in people management practices aligned with organizational strategies and workers' well-being is ratified, which results in the retention and satisfaction of people and, consequently, in the sustainability of the business.
\end{abstract}

Keywords: People Management. HR Policies and Practices. Turnover. 


\section{Introdução}

A Gestão de Pessoas, anteriormente denominada de Recursos Humanos, é uma área que vem evoluindo ao longo das últimas décadas e representa um constante desafio nas organizações (SILVA; SCHEFFER, 2015). Isso porque, na Era do Conhecimento, as pessoas assumiram papel estratégico e relevante no negócio, passando, portanto, a ser valorizadas e desenvolvidas por meio de políticas e práticas estruturadas (DEMO; FOGAÇA; COSTA, 2018).

No Brasil, o movimento acelerado da industrialização trouxe uma preocupação com tais práticas de gestão de pessoas nas organizações. Os princípios de divisão do trabalho, procedimentos de atração, remuneração, desenvolvimento e retenção de pessoas tiveram suas bases de origem norte-americanas e europeias alteradas (FERRAZZA; BURTET; SCHEFFER, 2015). A função da gestão de pessoas passou a ser fundamental, assumindo papéis e práticas mais relacionadas à esfera estratégica das organizações (MASCARENHAS, 2011; SILVA, 2017).

Logo, uma concepção contemporânea de negócio trouxe a inclusão de critérios relacionados ao cuidar bem das equipes, valorizar a gestão do conhecimento e oferecer o que a legislação trabalhista exige e mais um pouco. Tais concepções se concentram na forma como os indivíduos são geridos e em como aproveitar o potencial humano nas organizações, ou seja, propõe-se ir muito além da busca por uma mera solução técnica ou imediata por resultados econômico-financeiros (DE SANTI, 2018; LIMA FILHO; BARBOSA, 2019).

Em comparação a médias e grandes organizações, nas empresas de pequeno porte acentua-se a forte influência das crenças, normas e princípios do negócio sobre as políticas e práticas de gestão de pessoas. Nessas empresas a gestão de pessoas pode confrontar expressivos desafios, tais como: a escassez de recursos financeiros, tecnológicos e materiais; a inexistência de uma área de estruturada; e, a tendência de remunerações menos favoráveis (CAMPOS; STEFANO; ANDRADE, 2015).

Por outro lado, revelam-se alguns diferenciais competitivos em pequenos negócios, tais como: possibilidade da gestão de pessoas ser mais flexível, fácil adaptação do trabalhador a cultura organizacional e fácil percepção do resultado do trabalho realizado (BOFF; OLBERMANN; TAUFER, 2018).

Esses e outros fatores podem ser decisivos na escolha e na permanência dos trabalhadores nas empresas de pequeno porte, tendo em vista a necessidade de priorizar a gestão de pessoas e os processos que acompanham seu desenvolvimento, desde o nível estratégico até o operacional, bem como estabelecer políticas e práticas que favoreçam a satisfação e a retenção nos quadros organizacionais (FILIPPIM et al., 2018; LIMA; BARRETO, 2016).

Diante desse cenário, a seguinte questão norteou a pesquisa: "Qual a influência das políticas e práticas de gestão de pessoas na rotatividade de pessoal?". Logo, este estudo tem como objetivo compreender a influência das políticas e práticas de gestão de pessoas na rotatividade de pessoal em uma pequena empresa do comércio varejista de produtos alimentícios, localizada na cidade de Belo Horizonte - MG. Tal empresa apresenta um índice de rotatividade em torno de $4 \%$, tendo registrado uma significativa redução no último período divulgado até a data da investigação na organização.

Para cumprir o objetivo e responder a questão levantada, o artigo está composto por cinco seções, além desta introdução. A segunda seção destina-se ao referencial teórico que está fundamentado sobre a gestão de pessoas e a rotatividade de pessoal. Em seguida, a metodologia está abordada na terceira seção e na quarta, a apresentação e análise dos resultados. Na sequência estão as considerações finais, bem como as implicações e limitações do estudo, e por fim, as referências utilizadas na pesquisa.

\section{Gestão de Pessoas}

A gestão de pessoas tem uma função primordial nos negócios, uma vez que produz as características da organização, motivando os indivíduos a cooperar com os valores e objetivos estabelecidos, o que resulta em uma boa qualidade de vida no trabalho (SOUZA; PAIXÃO; SOUZA, 2011). Nesse sentido, Gil (2007) revela que a 
gestão de pessoas é a função gerencial responsável pela cooperação dos trabalhadores, tendo em vista o alcance dos objetivos tanto organizacionais, quanto individuais.

Esta concepção é ampliada por De Santi (2018) que destaca a gestão de pessoas como fator crucial para geração de valores diferenciais, contemplando a qualidade das relações humanas e o afloramento das competências individuais possibilitando modos que promovam a sustentabilidade organizacional no mercado competitivo.

Assim, tal função torna-se uma ferramenta indispensável para compreender e utilizar a capacidade humana no trabalho e possibilitar a organização obter vantagens nos determinados seguimentos em que atua, favorecendo o desenvolvimento e a potencialização das competências dos indivíduos (CARVALHO; SILVA, 2017; DEL MOURO; STEFANO, 2017).

Sob um enfoque mais amplo, Capaverde, Oliveira e Scheffer (2017) definem gestão de pessoas como os esforços e decisões, ou conjunto de políticas e práticas, direcionadas à construção de desempenho individual e organizacional, existindo enquanto processo imprescindível em todos os tipos de empresas e tendo implicação na gestão de modo geral. Envolve decisões que implicam na adoção de estilos de atuação de gestores até mesmo orientações para o desempenho individual e coletivo (CAPAVERDE; OLIVEIRA; SCHEFFER, 2017).

No momento em que os recursos tangíveis e a tecnologia não são mais considerados suficientes para garantir uma posição competitiva sustentável, as pessoas passam a ser competências essenciais de diferenciação estratégica (DEMO; MARTINS; ROURE, 2013). Desse modo, a organização precisa estar atenta à sua escuta, iniciando o intenso aprendizado de uma gestão adaptada ao mundo pós-industrial (LACOMBE, 2012).

Gerir pessoas é um constante desafio nas organizações. Isso porque, apesar do advento de um novo conceito para a Administração de Recursos Humanos e a compreensão de que as pessoas são fontes de vantagem e competitividade para os negócios, a gestão de pessoas ainda se defronta a desafios ambientais que envolvem novas soluções de sobrevivência, devido à complexidade dos relacionamentos entre diferentes pessoas e equipes, somadas a expectativas dos clientes (CAPAVERDE; OLIVEIRA; SCHEFFER, 2017; DA SILVA COUTINHO; DELFINO; COSTA, 2009).

Boxal (1996) e Silveira (2014) apontam que a contribuição da gestão de pessoas deve ultrapassar as noções reativas da implantação e adaptação, sendo avaliada também pela sua capacidade de gerar e sustentar recursos estratégicos, desenvolver competências organizacionais e criar organizações mais flexíveis, por apresentarem níveis superiores de cooperação, coordenação e inovação.

Nos últimos anos, observa-se mediante pesquisas, mudanças importantes no comportamento das organizações. Elas têm criado mais espaço para as pessoas e respeitado as individualidades, estimulando o desenvolvimento e abrindo um diálogo mais frequente e abrangente com as pessoas. Ao mesmo tempo, observa-se as pessoas mais exigentes na relação com as organizações, valorizando o diálogo, as condições de trabalho respeitosas e as oportunidades de aprendizagem e desenvolvimento profissional (DUTRA; DUTRA; DUTRA, 2017).

Guest (1987), Storey (1995) e Legge (2006) mencionam que ao assumirem papel estratégico e relevante nas organizações, as pessoas precisam de uma gestão devidamente suportada por práticas e políticas coesas e consistentes.

\section{Práticas de Gestão de Pessoas}

Segundo Lacombe (2005), nos primórdios da administração, iniciada pelos adeptos da administração científica, o foco dos esforços não era as práticas de gestão de pessoas, muito pelo contrário, considerava-se que gerir bem as pessoas estava condicionado a disponibilizar fatores e recursos para a realização da tarefa fim, tais como, luminosidade, materiais, espaço, dentre outros. Este fator reforçava a desvalorização das pessoas pelas organizações, as quais visavam seus esforços em buscar profissionais que simplesmente operassem máquinas, sem precisar contribuir em âmbito estratégico com os processos e estratégias da organização. Porém com o advento da globalização e as crescentes inovações tecnológicas mudou-se o foco de contratação de "mão de obra barata", 
buscando-se por pessoas com maior capacidade estratégica, capazes de gerar valor em cada processo (LACOMBE, 2005).

Em consonância com esta visão é necessário destacar que com as mudanças no cenário político e cultural, tornavase relevante desenvolver práticas que extraíssem o melhor de cada indivíduo para execução de suas atividades, como revelam Wood Jr., Tonelli e Cooke (2011). No Brasil, as práticas de gestão de pessoas tiveram início na década de 1940 com o movimento sindicalista e apresentaram alterações significativas somente entre os anos de 1980 e 2000, devido a inserção do país em novos mercados e pela busca de inovação, qualidade e eficiência (WOOD JR.; TONELLI; COOKE, 2011).

As práticas de gestão de pessoas surgiram como um "manual" composto por princípios e diretrizes, que buscavam desenvolver ações que estimulasse a motivação, o aprimoramento das competências e as habilidades dos indivíduos (LIMONGI-FRANÇA, 2006). Dessa forma, tais práticas passaram a se relacionar em um conjunto de subsistemas que correspondem individualmente por cada uma das funções de recursos humanos, desempenhando um papel relevante no processo de construção de identidade da organização (MARRAS, 2013). Neste contexto, a atração, capacitação, valorização e retenção de talentos assume uma conotação especial no âmbito da gestão de pessoas no novo milênio (DEMO, FERNANDES, FOGAÇA, 2017).

Vanalle, Santos e Santos (2011) salientam a relação existente entre as pessoas e as empresas nos dias atuais, em que, se baseia em uma troca de expectativas de ambas as partes, tornando essencial um ambiente que desenvolva uma boa comunicação, desafios, condições para o desenvolvimento de carreiras e oportunidades. Para isso, as empresas podem utilizar uma abundância de práticas de gestão de pessoas.

Entretanto, sete processos se fazem primordiais para o desenvolvimento eficiente e eficaz dessas práticas, são elas: recrutamento e seleção, capacitação, remuneração, avaliação de desempenho, gestão de carreira, cultura e clima organizacional, comunicação, conforme ilustra a Figura 1 (FLEURY; FISHER, 1996; VIEIRA; SILVA JÚNIOR; SILVA, 2014).

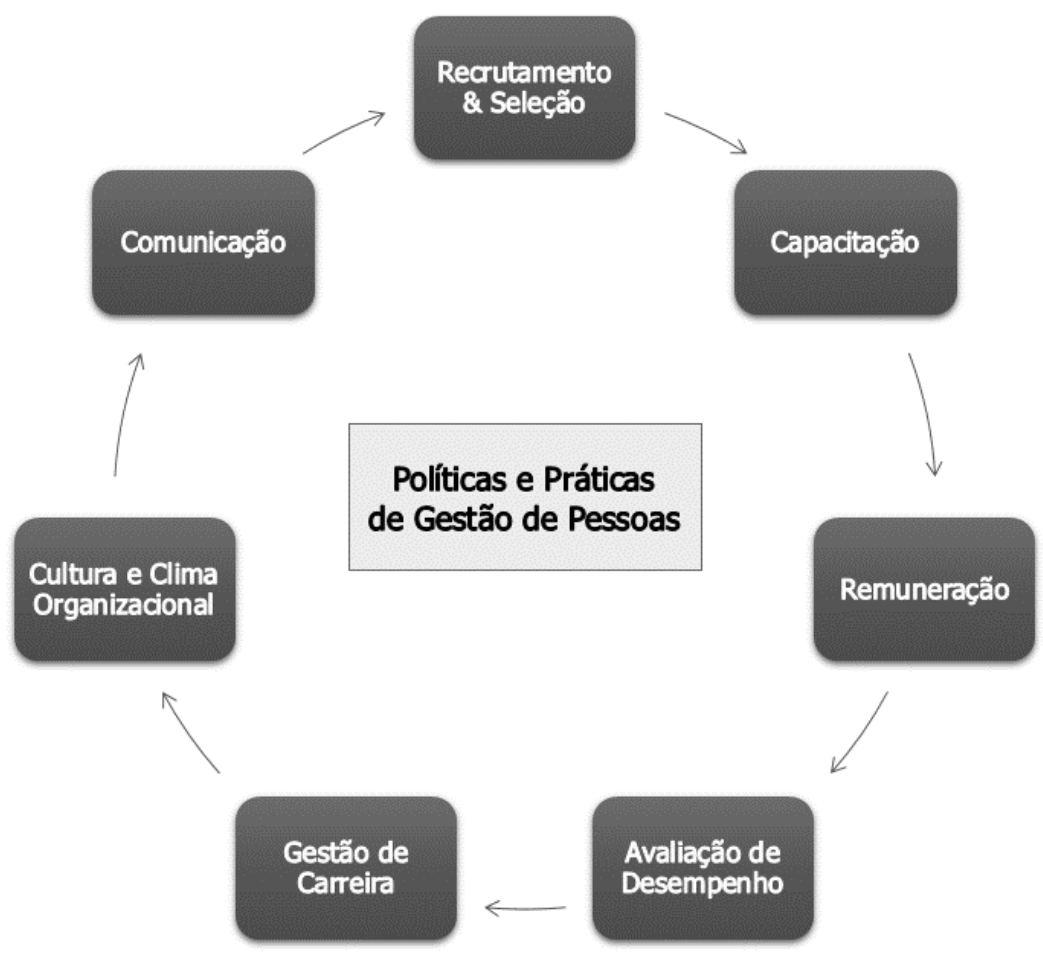

Figura 1 - Processos das políticas e práticas de gestão de pessoas

Fonte: Elaborado a partir de Fleury e Fisher (1996) e Vieira, Silva Júnior e Silva (2014). 
O processo de recrutamento e seleção ocorre quando a empresa tem necessidade da contratação de pessoas para prosseguimento ou aprimoramento de suas atividades, no qual, de um lado competem profissionais, e de outro, os empregadores (LIMONGI-FRANÇA, 2006). Para Lacombe (2005), as organizações empregadoras competem visando atrair os melhores indivíduos com boas condições de salários, trabalho e ambiente social, enquanto, os profissionais competem com suas habilidades, conhecimentos e experiências. O recrutamento e a seleção de pessoas são responsáveis pela capacitação e triagem de profissionais no mercado, por meio da seleção e encaminhamento de profissionais pela empresa (LACOMBE, 2005).

A capacitação de pessoas é descrita por Vanalle, Santos e Santos (2011) como o desenvolvimento de processos que visam aprimorar os conhecimentos e habilidades dos profissionais envolvidos na organização. Neste contexto, ela se mostra como um processo complexo e contínuo, essencial para manutenção do diferencial competitivo organizacional. Assim, as ações de capacitação são responsáveis por tornar os indivíduos mais eficientes naquilo que eles praticam, visando manter a qualidade em seus processos e, consequentemente, expandir a competitividade empresarial (VANALLE; SANTOS; SANTOS, 2011). Silva et al. (2018) evidenciam a necessidade de atualização constante da informação nas organizações por meio de programas de aprendizado, cujo objetivo garanta aos indivíduos o desenvolvimento de habilidades necessárias ao cumprimento de suas funções.

Vieira, Silva Júnior e Silva (2014) definem a gestão da remuneração como práticas, políticas e critérios adotados pela organização para remuneração ou benefícios a seus colaboradores. A remuneração é um dos fatores primordiais de atração e manutenção de profissionais na organização e esse processo pode ser definido pela legislação local e nacional, fatores mercadológicos e sindicais (VIEIRA; SILVA JÚNIOR; SILVA, 2014). Assim sendo, uma política adequada de remuneração, pode diferenciar a empresa no mercado competitivo. Do Nascimento, Canteri e Kovalesi (2019) ratificam que as recompensas no ambiente organizacional são grandes aliadas para motivar o desempenho individual e coletivo, a fim de aumentar a satisfação no trabalho e potencializar o crescimento da organização.

Vergara (1999) relata que a motivação do ser humano é intrínseca, no entanto, quaisquer que sejam as motivações ou razões pessoais para o trabalho, quase sempre, o maior estimulo é o dinheiro. A autora discorre também, que, subestimar a importância de uma boa remuneração e benefícios é um erro, pois estes, geralmente, são a chave principal para uma empresa de sucesso que recruta e retém seus colaboradores.

O processo de avaliação de desempenho consiste em um conjunto de processos e técnicas que tem por finalidade coletar dados do trabalho desenvolvido pelos trabalhadores, permitindo a elaboração de formulários de desempenho, além de permitir traçar metas e objetivos individuais (VIEIRA; SILVA JÚNIOR; SILVA, 2014). Marras (2011) ressalta que a avaliação possibilita um crescimento profissional e pessoal dos indivíduos, com vistas a melhorias no desempenho e no rendimento laboral.

A gestão da carreira, definida por Schein (2007) como um processo fundamental, que consistem em objetivos e metas definidas pelo colaborador em conjunto com a organização que o propicia crescimento pessoal e profissional. Em geral os processos relacionados a este planejamento devem estar alinhados com os interesses da empresa.

Segundo Dutra (1996), carreira deve ser vista como um caminho longo a ser percorrido em que o indivíduo precisa observar a necessidade da organização, e juntamente com ela, planejar suas metas para alcançar os objetivos almejados pela empresa e aprimorar sua trajetória profissional.

Os indivíduos precisam ser valorizados e estarem em um ambiente agradável para exercer suas funções sem medo de represálias, pois os seus sentimentos devem ser considerados, assim como suas expectativas (PAULA et al., 2011). Nesse sentido, os processos da gestão da cultura e do clima organizacional podem proporcionar efeitos significativos na motivação e na satisfação individual que, por si, geram uma melhor realização das tarefas e alcance dos objetivos organizacionais.

De um lado, a cultura é uma maneira informal e compartilhada de perceber a vida e a participação na organização, mantendo os membros unidos e influenciando o que pensam sobre si mesmos e seu trabalho (WAGNER III; HOLLENBECK, 2003). Por outro, o clima é importante para compreender o ambiente de trabalho e como está 
relacionado ao comportamento das pessoas, assim como a qualidade de vida e o seu reflexo no desempenho das organizações (SIQUEIRA, 2008). Assim, a cultura é um conceito relacionado a níveis mais profundos de comportamento dos grupos, enquanto o clima reflete a percepção de um grupo num determinado momento.

O último dos processos relacionados às práticas de gestão de pessoas é a comunicação, definida por LimongiFrança (2006) como um produto da sociedade em que as pessoas estão inseridas. A comunicação quando conduzida de maneira correta permite inovação nos processos, motivação dos colaboradores e possibilita a tomada de decisão com maior assertividade, logo, a interação entre gestores e colaboradores faz toda diferença no ambiente de trabalho (LIMONGI-FRANÇA, 2006). A troca de ideias, as propostas e dúvidas apresentadas pelos funcionários, geram um melhor entendimento da parte destes sobre os processos da empresa, tendo impacto direto na motivação e, consequentemente, na produtividade dos colaboradores (KNAANE, 1999).

As práticas de gestão de pessoas abrangem todas as áreas funcionais do negócio e apresentam um papel de diferencial competitivo no mercado. Os gestores que conseguem implantar de forma eficiente tais práticas podem extrair as melhores habilidades e competências de seus colaboradores, gerando um valor único e diferenciado para a organização (DEMO, FERNANDES, FOGAÇA, 2017).

Portanto, quando os indivíduos têm acesso a todos ou a maioria das sete práticas de gestão de pessoas apresentadas, a organização torna-se mais competitiva e os trabalhadores sentem-se mais satisfeitos e engajados a alcançarem os resultados. Entretanto, há um processo oneroso que reflete diretamente no clima organizacional e no relacionamento entre as pessoas, denominado rotatividade de pessoal. $O$ alto índice de rotatividade deve ser evitado a fim de que os processos da gestão de pessoas se tornem eficazes. Por esse motivo, a próxima seção será dedicada a discussão sobre esse fenômeno.

\section{Rotatividade de Pessoal}

Para que a organização possa extrair ao máximo o potencial de seus colaboradores, é necessário que se crie alternativas que minimizem um fenômeno que tem se tornado cada vez mais recorrente no atual mercado competitivo, o alto índice de rotatividade empresarial - turnover (PATIAS et al., 2015).

Turnover, correspondente ao termo rotatividade em português, sendo conceituado como o efeito que relaciona todas as movimentações de entrada e saída de colaboradores na organização, independentemente se os desligamentos foram motivados pelo trabalhador ou pela empresa (ORELLANO; MATTOS; PAZELLO, 2009).

Observa-se que um índice de rotatividade elevado pode ocasionar diversas consequências ruins para a organização. Pacheco (2009) destaca que os custos elevados e a perda de produtividade são alguns dos fatores com maior impacto. Além dos custos e perda de produtividade, o clima organizacional fica comprometido, uma vez que, os colaboradores ainda presentes na organização percebem ameaças ou oportunidades no mercado de trabalho que possam os influenciar (ROBBINS, 2005).

O crescimento da rotatividade encontra-se atrelado a fatores macroeconômicos e/ou organizacionais. Os fatores macroeconômicos se referem aos períodos de aquecimento econômico, no qual as taxas de desemprego tendem a reduzir, gerando por consequência um aumento dos índices de rotatividade empresarial, devido ao aumento de demissões voluntárias que ocorrem nesse cenário (FERREIRA; FREIRE, 2001). Já, os fatores organizacionais são relativos a políticas e filosofias praticadas na organização, tais como as salariais, disciplinares, ausência de planos de desenvolvimento de carreiras, ausência de incentivos, treinamentos ruins e distanciamento entre o colaborador e a cultura organizacional (ORELLANO; MATTOS; PAZELLO, 2009).

Além desses fatores, Mobley (1992) destaca que para avaliar a rotatividade com eficiência é necessário analisar não apenas práticas organizacionais e econômicas, mas também, os aspectos individuais de cada colaborador. Ao se manter em equilibro, o índice de turnover pode resultar no sucesso dos negócios e na consolidação de uma gestão de pessoas adequada (MOBLEY, 1992). No entanto, não se pode obter uma taxa nula de rotatividade, visto que, a ausência da mesma pode acarretar sérios problemas a uma empresa, onde, é necessário se calcular a qualidade 
dos colaboradores perdidos, uma vez que, a manutenção de mão de obra improdutiva gera elevados custos e podem indicar uma organização estagnada e com absenteísmo (PATIAS et al., 2015).

Neste contexto, Marangoni e Berimbau (2018) destacam a importância de mapear todas as atuais metodologias aplicadas em recursos humanos na organização e atentar-se a todas as novas técnicas e abordagens que permeiam a gestão de pessoas utilizadas no mercado de trabalho, tornando possível controlar as taxas de turnover por meio do alinhamento de novos conhecimentos com os processos empresariais, o que possibilitará um ambiente organizacional motivador e produtivo.

É necessário observar as diversas situações impulsionadoras de turnover e avaliar o nível desejável de rotatividade na organização. Empresas que desejam aperfeiçoar seu valor de negócio devem estar sempre atentas a gestão de seu capital humano, e para isto, é necessário controlar a rotatividade de pessoas para que se amplie a eficiência nos processos e se mantenha o que mais valioso existe em uma organização: seus talentos, valores e conhecimentos (MOBLEY, 1992; PATIAS et al., 2015).

Sendo assim, o controle da rotatividade de pessoal é fundamental para o bom desempenho da organização e isso pode ser feito por meio das ferramentas disponíveis na gestão de pessoas, dentre elas: avaliações de desempenho e pesquisas de clima organizacional. A partir dessas informações, é possível aprimorar os processos relacionados as práticas de gestão de pessoas, não só com o conhecimento dos motivos que levam a rotatividade, mas também com o levantamento de motivos que atraem as pessoas para a organização.

\section{Procedimentos metodológicos}

Este estudo se caracteriza como uma pesquisa descritiva de abordagem qualitativa. Realizou-se um estudo de caso, cujo método apresenta aspectos da realidade de cada indivíduo que não podem ser quantificados, em que se atenta à compreensão e explicação das relações dinâmicas sociais (YIN, 2015).

A pesquisa foi desenvolvida em uma organização do comércio varejista de produtos alimentícios localizada no município de Belo Horizonte - MG, classificada como empresa de pequeno porte em razão do faturamento anual estar compreendido entre $\mathrm{R} \$ 360$ mil e $\mathrm{R} \$ 4,8$ milhões (SEBRAE, 2019). Os critérios de escolha da organização foram: a) existência de políticas e práticas de recursos humanos; b) índice de rotatividade maior que 1\%; c) disponibilidade da diretoria em fornecer informações e documentos para o alcance do objetivo proposto.

Do total de 36 colaboradores em exercício na organização, 15 tiveram a oportunidade de relatar, de acordo com suas experiências profissionais e com suas visões particulares, fatores e práticas organizacionais da gestão de pessoas. Eles foram escolhidos intencionalmente em razão de: a) participação de pelo menos um representante de cada função; b) disponibilidade para participar da entrevista durante o expediente após autorização da supervisão.

Foi acordado com os entrevistados que os seus nomes seriam mantidos em sigilo, não sendo, portanto, aqui identificados. Assim definido, cada entrevistado foi designado de "colaborador" seguido de um número de 1 a 15, como mostra o Quadro 1. 
Quadro 1 - Perfil dos entrevistados

\begin{tabular}{|c|c|c|c|}
\hline $\begin{array}{l}\text { Código dos } \\
\text { entrevistados }\end{array}$ & Sexo & Função & Tempo de empresa \\
\hline Colaborador 1 & Masculino & Gerente Geral & 6 anos e 2 meses \\
\hline Colaborador 2 & Feminino & Auxiliar Administrativo & 3 anos e 11 meses \\
\hline Colaborador 3 & Feminino & Auxiliar Administrativo & 2 anos e 5 meses \\
\hline Colaborador 4 & Masculino & Conferente & 4 anos e 3 meses \\
\hline Colaborador 5 & Feminino & Auxiliar de Limpeza & 5 anos \\
\hline Colaborador 6 & Feminino & Auxiliar de Limpeza & 11 meses \\
\hline Colaborador 7 & Masculino & Fiscal de Loja & 4 anos \\
\hline Colaborador 8 & Masculino & Fiscal de Loja & 5 anos e 4 meses \\
\hline Colaborador 9 & Feminino & Operadora de Caixa & 1 ano e 1 mês \\
\hline Colaborador 10 & Feminino & Operadora de Caixa & 1 ano e 7 meses \\
\hline Colaborador 11 & Feminino & Operadora de Caixa & 2 anos \\
\hline Colaborador 12 & Masculino & Repositor & 1 ano e 9 meses \\
\hline Colaborador 13 & Feminino & Repositora & 3 anos e 6 meses \\
\hline Colaborador 14 & Masculino & Repositor & 3 anos \\
\hline Colaborador 15 & Masculino & Repositor & 2 anos e 10 meses \\
\hline
\end{tabular}

Fonte: Dados da pesquisa.

Os instrumentos de pesquisa utilizados foram:

a) pesquisa documental: procedimento para coleta de dados em documentos relacionados ao estudo, sendo um importante instrumento para identificar o indicador de turnover organizacional e as práticas de gestão de pessoas incidentes na empresa;

b) observação: envolvimento com o ambiente e observação dos processos diários da organização para extrair dados pertinentes ao caso. A observação da rotina organizacional ocorreu do dia 26 de novembro a 01 de dezembro de 2018 (segunda a sábado) com duração diária de três horas, onde um dos autores examinou e anotou as impressões sobre o que foi observado em todos os departamentos percorridos;

c) entrevista semiestruturada: entrevista individual por meio de um roteiro, permitindo a exposição de fatos cotidianos e observações úteis para a análise de dados.

Ao fazer uso de múltiplas fontes de evidência (pesquisa documental, entrevistas semiestruturada com colaboradores, observação) se tornou propícia a realização da triangulação das fontes dos dados, a fim de que as descobertas do estudo de caso fossem apoiadas por mais de uma fonte de evidência. Nesse sentido, Yin (2015) indica que o emprego da triangulação torna o achado ou conclusão do estudo de caso mais convincente e acurado, pois se baseia em diversas fontes diferentes de informação.

Além da triangulação, no que tange aos relatos obtidos por intermédio das entrevistas semiestruturadas com os colaboradores da organização realizou-se a análise de conteúdo, cuja técnica é produzir inferências de um texto focal para seu contexto social de maneira objetivada por meio de procedimentos sistemáticos, metodicamente explícitos e replicáveis (BAUER; GASKELL, 2014).

As entrevistas individuais semiestruturadas foram conduzidas por meio de um roteiro com oito perguntas abertas oriundas da fundamentação teórica (FLEURY; FISHER, 1996; LACOMBE, 2005; LIMONGI-FRANÇA, 2006; MARRAS, 2011; VIEIRA; SILVA JÚNIOR; SILVA, 2014), em conformidade com o objetivo proposto neste estudo, sendo elas: a) como ocorre o processo de recrutamento e seleção da empresa? Descreva com detalhes; b) os colaboradores recebem capacitação/treinamento para exercer suas funções? Relate como é o processo; c) como 
os colaboradores são remunerados? Você considera justo o valor da remuneração e os benefícios oferecidos?; d) existe avaliação de desempenho dos colaboradores? Como ela é realizada?; e) há oportunidades de crescimento e plano de carreira na empresa?; f) como é o ambiente da empresa? Você conhece e vivencia a cultura da empresa?; g) como é o processo de comunicação entre os colaboradores e a supervisão? Comente; e, h) aponte os motivos pelos quais você trabalha nesta organização.

Ademais, as entrevistas ocorreram na própria organização em que os entrevistados exercem suas atividades profissionais entre os meses de novembro e dezembro de 2018, durando em média 30 minutos. Todas foram gravadas e transcritas a fim de que fosse mantida a exatidão dos relatos obtidos.

Tornou-se assim necessário definir categorias de análise provenientes dos relatos dos entrevistados para se garantir a estruturação dos dados. Este procedimento, segundo Bardin (2011), é caracterizado como um conjunto de métodos determinados por semelhanças relativas a um tema e/ou título específico. Para esta pesquisa, as categorias foram estabelecidas tendo a literatura como norteadora, bem como os relatos das entrevistas realizadas, sendo elas: a) recrutamento e seleção; b) capacitação; c) remuneração e benefícios; d) avaliação de desempenho; e) gestão de carreira; f) cultura e clima organizacional; e, g) comunicação.

\section{Apresentação e análise dos resultados}

Esta seção tem por objetivo apresentar os resultados da pesquisa documental, bem como das entrevistas realizadas com os colaboradores da organização e da observação em campo.

No que tange a pesquisa documental, identificou-se a existência de um documento, denominado "Política de Recursos Humanos", composto por 54 páginas, as quais descrevem as práticas e mecanismos de gestão de pessoas praticados pela organização, tais como: processos de contratação e capacitação dos colaboradores, salários e benefícios oferecidos, estruturação dos cargos, entre outros.

Tal documento foi criado em janeiro/2018 pelo filho do diretor da organização, atual gerente geral. Mesmo não dispondo de um departamento estruturado de gestão de pessoas, após se graduar em Administração, o gerente geral identificou a necessidade de oficializar os processos de recursos humanos e criar esse guia para conduzir as ações da pequena empresa. Em anexo a essa política, há um espaço destinado ao preenchimento manual de dados mensais: número de admissões e demissões, acidentes de trabalho, promoções, absenteísmo e rotatividade no mês.

\section{Práticas de Gestão de Pessoas}

As seguintes categorias emergidas por meio da literatura (FLEURY; FISHER, 1996; VIEIRA; SILVA JÚNIOR; SILVA, 2014) fundamentaram a análise dos resultados: "recrutamento e seleção", "capacitação", "remuneração e benefícios", "avaliação de desempenho", "gestão de carreira", "cultura e clima organizacional" e "comunicação".

$\mathrm{Na}$ categoria "recrutamento e seleção", a maioria dos colaboradores aponta que o processo de captação de currículos e condução das entrevistas passou a ser mais organizado e consistente a partir do ano de 2018. Vários comentários respaldam essa concepção, como por exemplo, o colaborador 11: "para ser contratado era muito simples, bastava você procurar o diretor, e pronto. Já podia começar amanhã! Parece que agora eles [diretoria] estão dando mais importância para contratar a pessoa certa para o cargo"; o colaborador 3: "antes [nos anos anteriores a 2018] era muito fácil ser contratado, você deixava o currículo hoje e amanhã já conversava com o diretor e era aprovado. Agora mudou! Eles [diretoria] estão recolhendo os currículos, fazendo uma análise e fazendo entrevistas com mais rigor"; e o colaborador 1: "após a criação da política de RH foi elaborado um banco de currículos e, quando há vagas, é feita uma análise e elabora-se uma entrevista por competência, conforme as exigências do perfil da vaga".

Os comentários dos entrevistados ratificam o documento analisado, o qual descreve o processo de recrutamento e seleção da empresa em seis etapas: a) definição do perfil da vaga; b) captação de currículos de residentes da região e acesso ao banco de talentos; c) triagem de currículos conforme o perfil definido; d) elaboração de um roteiro de 
entrevista por competências a ser aplicado; e) agendamento e condução de entrevistas e possíveis testes de aptidão; d) retorno para os candidatos.

Fica evidente que a prática de recrutamento e seleção da organização, a partir da criação da Política de Recursos Humanos, se tornou mais organizada, eficaz e respeitável por parte dos colaboradores, sendo perceptível a importância atribuída a tal processo cuja conotação é extremamente relevante para a atração de talentos no novo milênio (DEMO, FERNANDES, FOGAÇA, 2017). Desse modo, como afirma Limongi-França (2006) a organização pode atrair os melhores indivíduos com as habilidades, conhecimentos e experiências para o cargo, ou seja, a pessoa certa para função certa. É perceptível a importância atribuída ao processo de recrutamento e seleção

Em relação a categoria "capacitação", a maioria dos entrevistados revela que a empresa não promove um processo contínuo de aprendizagem, somente há treinamentos em caso de correções processuais ou elaboração de novos processos, como relatam, respectivamente, o colaborador 8 e 10: "não há treinamentos contastes. Na verdade, somos orientados pelo nosso líder e pronto! Se alguém fizer alguma coisa, eles [diretoria] contratam um treinamento para nós [colaboradores]"; "aqui só tem treinamento quando tem algum processo novo a ser realizado ou tem tarefas sendo feitas erradas".

Os relatos apontam a inexistência de um processo permanente de aprimoramento dos conhecimentos e habilidades dos indivíduos, como sugere Vanalle, Santos e Santos (2011). Contudo, mesmo não estabelecendo uma cultura da aprendizagem e os treinamentos formais serem escassos, o documento analisado e a observação da rotina dos colaboradores evidenciam a prática constante de instrução e ensinamentos por parte da liderança aos seus liderados. Nesse sentido, a Política de Recursos Humanos determina dois tipos de processo de aprendizagem: a) orientação no local de trabalho pela liderança (on the job): o colaborador aprende os métodos de trabalho constantemente na prática com o líder responsável; e, b) treinamentos específicos contratados conforme a necessidade da organização: padronização de novos processos ou correções de falhas.

O processo de aprendizagem relacionado a orientação no local de trabalho pela liderança foi ratificado pelas observações in loco em todos os dias de investigação realizados. A todo instante, os colaboradores eram instruídos pelos seus superiores que acompanhavam de perto a realização das tarefas. Ou seja, essa repetida ação pode proporcionar aos indivíduos a oportunidade de aprimorarem suas habilidades profissionais, mantendo a qualidade na execução dos processos e tornando-os ainda mais eficientes no que praticam, como evidenciam Vanalle, Santos e Santos (2011).

No que tange a categoria "remuneração e benefícios", todos os entrevistados relataram que a partir do ano de 2018 a empresa passou a dispor de uma remuneração atrativa e benefícios favoráveis: "hoje temos um salário melhor e benefícios que valem a pena" (Colaborador 7); "nosso salário aumentou em 2018 e passamos a receber uma cesta básica, isso fez uma grande diferença" (Colaborador 10); "hoje em dia nossa remuneração é melhor e temos benefícios bons também" (Colaborador 15).

Ao perceber que o maior estímulo para o trabalho quase sempre é o dinheiro, como respalda Vergara (1999), a direção da empresa definiu algumas mudanças relativas a remuneração e benefícios formalizando-as na Política de Recursos Humanos:

\footnotetext{
em relação a remuneração adotamos [empresa] as seguintes medidas: pesquisa salarial anual no comércio varejista regional e reajustes salariais anuais; contratação de pessoas residentes no mesmo bairro e extinção do benefício de vale transporte; inserção do benefício de uma cesta básica mensal e um plano de saúde coparticipativo. Essas três medidas foram suficientes para minimizar as reclamações das questões salariais e, aí, percebermos o quanto o dinheiro é essencial para a satisfação dos trabalhadores (Colaborador 1).
}

É notório o quanto a empresa compreendeu e implantou medidas que destacam as recompensas no ambiente organizacional, visto que elas são um dos fatores primordiais de atração, satisfação e retenção de talentos, como revelam Vieira, Silva Júnior, Silva (2014) e Do Nascimento, Canteri e Kovalesi (2009). Além disso, elas são grandes aliadas para a motivação e o desempenho dos trabalhadores. 
$\mathrm{Na}$ categoria "avaliação de desempenho" todos os entrevistados relataram que não há um processo de avaliação de desempenho na empresa. Entretanto, o colaborador 1 revelou a necessidade de implantação: "não temos uma avaliação do desempenho dos colaboradores e não foi previsto nada sobre isso na política. Mas, a intenção é definir as competências para cada função e iniciar o processo de avaliação a partir do ano de 2019. Para isso, iremos incluir um aditivo na política".

Assim, apesar da ausência da prática de avaliação de desempenho a empresa reconhece a importância dessa prática, pois além do diagnóstico sobre a eficiência e eficácia do trabalho de cada indivíduo, é possível também reconhecer os talentos e os profissionais de destaque, bem como identificar aqueles que precisam ser acompanhados mais de perto. Logo, ao investir futuramente nesse processo, a empresa poderá obter consideráveis melhorias no desempenho e no rendimento dos trabalhadores, como afirmam Marras (2011) e Vieira, Silva Júnior, Silva (2014).

Sobre a categoria "gestão de carreira" os entrevistados ressaltaram a possibilidade de assumir outras funções, mesmo atuando em uma pequena empresa. O colaborador 1 justifica as oportunidades de promoção devido a estabilidade da organização nos últimos anos, mesmo em meio à crise econômica do país, proporcionando três mudanças de funções para cargos gerenciais e quatro para cargos operacionais.

A Política de Recursos Humanos não apresenta um plano de carreiras estruturado, mas determina alguns critérios para promoção, sendo eles: escolaridade, postura e comprometimento, tempo de trabalho na empresa. Ainda assim, a presença de um plano de carreiras seria fundamental para estabelecer e explicitar o caminho que cada colaborador poderia percorrer dentro da organização, determinando as competências necessárias para cada posição hierárquica e também a expectativa da empresa em relação àquela posição. Ou seja, os indivíduos poderiam planejar suas metas para alcançar os objetivos almejados pela organização e aprimorar suas trajetórias profissionais (DUTRA, 1996).

A respeito da "cultura e clima organizacional", os entrevistados relataram conhecer os valores e as crenças da organização desde o primeiro dia de trabalho e são estimulados a compartilhar os comportamentos e a identidade da empresa nos relacionamentos internos e externos. Entretanto, eles revelaram que não há mensuração da satisfação dos trabalhadores com o ambiente de trabalho por parte da organização. Nessa perspectiva, a Política de Recursos Humanos não dispõe de nenhum preceito sobre essa prática, já a observação realizada revela um ambiente de trabalho adequado e saudável, onde se destacam os laços entre as pessoas, a comunicação interna predominantemente informal e o compartilhamento dos objetivos das equipes.

Assim, fica evidente a necessidade de a empresa fazer uso de um indicador que a ajude na compreensão do ambiente de trabalho e dos comportamentos dos trabalhadores, assim como a qualidade de vida e o seu reflexo no desempenho coletivo. Como sugere Siqueira (2008), a pesquisa de clima é a ferramenta mais apropriada para realização dessa análise.

Por fim, na categoria "comunicação" todos os entrevistados afirmaram que a comunicação informal é predominante e, ao mesmo tempo, eficaz na empresa. Além das informações divulgadas diariamente pelos líderes aos liderados, sendo ratificada pela observação de campo realizada, a Política de Recursos Humanos estabelece outros dois mecanismos de comunicação: perfil em uma rede social e quadro de avisos, considerados essenciais para a troca de informações corporativas, como propõe Knaane (1999).

É explícita a contribuição da Política de Recursos Humanos para o sucesso das práticas de gestão de pessoas na organização e, sobretudo, das ações criadas e adotadas a partir do ano de 2018. Tal documento legitimiza a conotação especial que a atração, a valorização e a retenção de talentos assumiu nos últimos anos no âmbito da gestão de pessoas, como indicam Demo, Fernandes e Fogaça (2017).

De modo geral, por meio dos resultados supracitados, constatou-se a presença de cinco práticas de gestão de pessoas concebidas pela organização, sendo elas: a) processo de recrutamento e seleção em seis etapas; b) orientações no local de trabalho por parte dos líderes aos liderados; c) ajustes na remuneração e inclusão de novos benefícios (cesta básica e plano de saúde); d) critérios estabelecidos para promoções; e) comunicação interna formal (quadro de aviso) e informal.

Logo, revela-se a preocupação da diretoria da organização com os trabalhadores, impulsionando-os a atuarem de forma colaborativa, motivada e com vontade de fazer a diferença, apesar da ausência de um setor específico de 
gestão de pessoas. As práticas de gestão de pessoas, aparentemente simples e restritas, podem ser capazes de garantir o alinhamento das ações às necessidades e realidades de uma empresa de pequeno porte. Ou seja, a organização dessas práticas contribui para que se torne possível mediar as relações interpessoais, compartilhar informações, criar padrões de trabalho e acompanhar a evolução do capital humano disponível.

\section{Rotatividade de Pessoas}

Conforme disposto no anexo da Política de Recursos Humanos da empresa, a média semestral do índice de rotatividade (turnover) é apresentado na Tabela 1.

Tabela 1 - Índice de rotatividade da empresa

\begin{tabular}{c|c}
\hline Período & Média do índice de rotatividade por período \\
\hline Janeiro/17 a Junho/17 & $3,69 \%$ \\
\hline Julho/17 a Dezembro/17 & $3,89 \%$ \\
\hline Janeiro/18 a Junho/18 & $3,28 \%$ \\
\hline
\end{tabular}

Fonte: Dados da pesquisa.

Constata-se uma rotatividade consideravelmente baixa e estável, mantendo-se em torno de 4\%. Em geral, mesmo em meio aos fatores que dificultam a retenção de profissionais nas empresas do comércio varejista e a crise econômica instaurada no país, a pequena empresa manteve um índice de rotatividade equilibrado nos últimos dezoitos meses. Entretanto, a pequena variação negativa entre os anos de 2017 e 2018 pode estar atrelada a dois fatores: a) redução das oportunidades de emprego o que deixa os colaboradores inseguros para uma eventual demissão; b) reflexo positivo das medidas implantadas decorrentes da Política de Recursos Humanos criada em 2018.

Em relação a este último fator, ao serem indagados sobre os motivos que os fazem continuar trabalhando na organização, todos os entrevistados apontaram a localização da empresa e, consequentemente, a qualidade de vida proporcionada pela ausência do tempo de deslocamento como o principal motivo de trabalharem na organização. Além disso, todos revelaram que a criação da Política de Recursos Humanos em 2018 despertou o sentimento de cuidado e atenção por parte da diretoria para os colaboradores. Ou seja, ao mapear e implantar políticas aplicadas em recursos humanos, torna-se possível controlar as taxas de turnover e, por conseguinte, possibilita um ambiente organizacional motivador e produtivo, como respaldam Marangoni e Berimbau (2018).

Tabela 2 - Motivos de retenção segundo os entrevistados

\begin{tabular}{c|c}
\hline Motivo & Frequência \\
\hline Localização da empresa e Qualidade de Vida & 15 \\
\hline Remuneração e Benefícios & 12 \\
\hline Oportunidade de Crescimento & 8 \\
\hline
\end{tabular}

Fonte: dados da pesquisa.

A Tabela 2 revela a frequência dos motivos de retenção segundo os entrevistados. Além da localização e qualidade de vida, destacam-se a remuneração e benefícios oferecidos, bem como a oportunidade de crescimento profissional. Ou seja, os fatores de retenção dos trabalhadores estão diretamente associados aos processos formalizados pela Política de Recursos Humanos a partir do ano de 2018. Logo, como respalda Mobley (1992), o equilíbrio e a pequena variação negativa no índice de rotatividade da empresa apresentado na Tabela 2 é resultado da consolidação de uma gestão de pessoas adequada aos aspectos individuais dos colaboradores, o que contribui para o sucesso dos negócios.

Cabe destacar que os dados acima sugerem aos gestores que a oportunidade de crescimento, o reconhecimento, a recompensa, as promoções, o equilíbrio entre a vida pessoal e profissional representam em alta escala o princípio de harmonia entre as perspectivas da organização e de seus colaboradores. Lidar com pessoas requer gerar e 
sustentar níveis superiores de cooperação, coordenação, flexibilidade e inovação (BOXAL, 1996; SILVEIRA, 2014).

Portanto, é irrefutável a associação existente entre a efetiva gestão do capital humano e o aperfeiçoamento do valor de negócio da organização por meio do controle da rotatividade de pessoas e da eficiência nos processos de atração, manutenção e retenção de talentos.

\section{Considerações finais}

Este estudo objetivou compreender a influência das políticas e práticas de gestão de pessoas na rotatividade de pessoal em uma pequena empresa, localizada na cidade de Belo Horizonte-MG. Para isso, realizou-se um estudo de caso por meio da pesquisa documental, entrevistas semiestruturadas e observação in loco.

Percebe-se uma forte influência das políticas e práticas de gestão de pessoas na rotatividade de pessoal na organização, estando atrelada, principalmente, a criação do documento "Política de Recursos Humanos" elaborado pelo gerente geral da empresa no início do ano de 2018. Ao formalizar os processos de gestão de pessoas constatase a pequena variação negativa entre os anos de 2017 e 2018 no índice de rotatividade da empresa. Isto é, a empresa continuou apresentando rotatividade nesse período, porém o número de admissões e demissões foi relativamente menor.

Logo, é evidente que as ações de gestão de pessoas implantadas e divulgadas na organização se tornaram fundamentais para a retenção dos talentos. Em outras palavras, as taxas de rotatividade sofrem consequências diretas das estratégias adotadas em prol da atração, do desenvolvimento e da permanência das pessoas no trabalho.

Isto significa que ao contratar as pessoas certas desde o início, definir a compensação correta e um pacote de benefícios, bem como mostrar aos colaboradores como e onde eles podem chegar em suas carreiras pode contribuir para a redução da rotatividade de pessoal. Marangoni e Berimbau (2018) e Demo, Fernandes e Fogaça (2017) respaldam que ao mapear e implantar ações de atração, a valorização e a retenção de talentos torna-se possível controlar as taxas de rotatividade, bem como possibilitar um ambiente organizacional positivo.

Assim, na organização investigada é notório que os motivos de retenção dos colaboradores estão associados diretamente as políticas e práticas de gestão de pessoas. As etapas do processo de recrutamento e seleção, a pesquisa salarial anual e a inclusão de benefícios, bem como a oportunidade de crescimento na organização afetam a decisão dos trabalhadores em permanecer em suas posições e não ir em busca de novas oportunidades, o que resulta consequentemente em reduções na taxa de rotatividade de pessoal.

Os resultados obtidos não se limitam ao cenário das organizações de pequeno porte, pois a necessidade de priorizar a gestão de pessoas e os processos que acompanham seu desenvolvimento se apresentam como diferenciais competitivos para a adaptação e permanência dos trabalhadores em negócios de diferentes portes (micro, pequenas, médias e grandes empresas).

Este estudo ratifica a importância do investimento em práticas de gestão de pessoas alinhadas a estratégias organizacionais e ao bem-estar dos trabalhadores, o que resulta no alcance dos objetivos estabelecidos, na retenção e satisfação das pessoas e, consequentemente, na sustentabilidade dos negócios. Além disso, os resultados respaldam a função essencial da gestão de pessoas para a prosperidade dos negócios, ao assumir papeis e práticas relacionadas ao âmbito estratégico (MASCARENHAS, 2011; SILVA, 2017), especialmente para as pequenas empresas, nas quais muitas delas ainda não dispõem de uma área estruturada ou algum profissional de gestão de pessoas.

Os gestores e empreendedores devem sempre estar atentos a valorização e ao reconhecimento dos indivíduos por meio de ações que possibilitem a execução do trabalho de forma eficiente e coesa, bem como o desenvolvimento assertivo no cumprimento dos processos. À vista disso, tanto as práticas de gestão de pessoas quanto a relação dos gestores com suas equipes podem intervir positivamente no engajamento dos colaboradores, evidenciando a importância do aprimoramento da relação líder-liderado. 
Sugere-se a diretoria da organização investigada, o aperfeiçoamento das práticas citadas na Política de Recursos Humanos visto que a simples implantação de tais práticas resultou em um efeito positivo na retenção e satisfação dos trabalhadores. Logo, propõem-se as seguintes ações futuras: a) concepção de uma cultura de aprendizagem aos trabalhadores com incentivo permanente a gestão do conhecimento; b) execução da avaliação de desempenho anual; c) implantação de outros benefícios sociais; d) criação de um plano de carreiras estruturado; e) oficialização e formalização da cultura organizacional por escrito; f) execução da pesquisa de clima organizacional anual; g) criação de um canal de comunicação interna oficial. Ao investir nessas ações, a gestão de pessoas da organização assumirá um sentido especial, segundo o papel da área no cenário atual como respaldam os autores Demo, Fernandes e Fogaça (2017).

Dentre as limitações, esta pesquisa apresentou: observação da rotina de trabalho em apenas uma semana e não por um período longitudinal; participação restrita dos colaboradores mediante autorização da liderança para realização da entrevista no horário de trabalho; e, histórico limitado referente ao índice de rotatividade - disponível até a data da realização da pesquisa $\left(1^{\circ}\right.$ semestre de 2018$)$.

Para futuros estudos, recomenda-se a utilização de um maior período longitudinal de análise da organização e da investigação em profundidade de outras variáveis (motivos de demissão, admissão e absenteísmo) que podem interferir na rotatividade de pessoas, além de uma abordagem comparativa da rotatividade e práticas de gestão de pessoas entre organizações do mesmo setor ou organizações de setores diferentes.

\section{Referências}

BARDIN, L. Análise de conteúdo. Tradução de Luís Antero Reto e Augusto Pinheiro. 3. ed. São Paulo: Edições 70, 2011.

BAUER, M. W.; GASKELL, G. Pesquisa qualitativa com texto, imagem e som: um manual prático. 12. ed. Petrópolis: Vozes, 2014.

BOFF, D.; OLBERMANN, J. V.; TAUFER, L. Do cotidiano ao formal: práticas de gestão de pessoas em duas pequenas empresas. Revista da Micro e Pequena Empresa, v. 12, n. 1, p. 18-32, 2018.

BOXALL, P. The strategic HRM debate and the resource-based view of the firm. Human Resource Management Journal, v. 6, n. 3, p. 59-75, 1996.

CAMPOS, E. A. R.; STEFANO, S. R.; ANDRADE, S. M. Cultura organizacional no contexto de políticas e práticas de gestão de pessoas. Reuna, v. 20, n. 3, p. 65-82, 2015.

CAPAVERDE, C. B.; OLIVEIRA, L. P.; SCHEFFER, A. B. B. Subjetividade e enfrentamento da morte: construindo gestão de pessoas na cotidianidade. REAd. Revista Eletrônica de Administração, v. 23, p. 188209, 2017.

CARVALHO, A. D.; SILVA, B. A. D. R. A gestão de pessoas e o relacionamento interpessoal no cooperativismo. Revista de Carreiras e Pessoas, v. 7, n. 3, p. 139-150, 2017.

DA SILVA COUTINHO, L.; DELFINO, L. M.; COSTA, W. L. Pessoas: principal fonte de vantagem competitiva organizacional. In: VI Simpósio de Excelência em Gestão De Tecnologia - SEGeT, 6, 2009, Resende/RJ. Anais... Resende: 2009.

DE SANTI, P. L. R. A gestão de pessoas e as ciências humanas: discussão conceitual entre projeto de modernidade e "jeitinho brasileiro". Revista de Carreiras e Pessoas (ReCaPe), v. 8, n. 2, 2018.

DEL MOURO, G. C. F.; STEFANO, S. R. Práticas de gestão de pessoas nas organizações do ramo de concessionárias de automóveis. Revista Eletrônica Científica do CRA-PR, v. 4, n. 1, p. 20-31, 2017.

DEMO, G.; FERNANDES, T.; FOGAÇA, N. A influência dos valores organizacionais na percepção de políticas e práticas de gestão de pessoas. REAd. Revista Eletrônica de Administração, v. 23, n. 1, p. 89-117, 2017.

DEMO, G.; FOGAÇA, N.; COSTA, A. C. Políticas e práticas de gestão de pessoas nas organizações: cenário da produção nacional de primeira linha e agenda de pesquisa. Cadernos EBAPE.BR, v. 16, n. 2, p. 251-263, 2018. 
DEMO, G.; MARTINS, P. DE R.; ROURE, P. Políticas de gestão de pessoas, comprometimento organizacional e satisfação no trabalho na Livraria Cultura. Revista Alcance - Eletrônica, v. 20, n. 2, p. 237-254, 2013.

DO NASCIMENTO, R. F.; CANTERI, M. H. G.; KOVALESKI, J. L. Impacto dos sistemas de recompensas na motivação organizacional: revisão sistemática pelo método PRISMA. Gestão \& Conexões - Management and Connections Journal, v. 8, n. 2, p. 44-58, 2019.

DUTRA, J. S. Administração de carreira: uma proposta para repensar a gestão de pessoas. São Paulo: Atlas, 1996.

DUTRA, J. S.; DUTRA, T. A.; DUTRA, G. A. Gestão de pessoas: realidade atual e desafios futuros. São Paulo: Atlas, 2017.

FERRAZZA, D. S.; BURTET, C. G.; SCHEFFER, A. B. B. O que as organizações entendem por Gestão de Talentos?. REAd. Revista Eletrônica de Administração, v. 21, n. 1, p. 222-247, 2015.

FERREIRA, M. C.; FREIRE, O. N. Carga de trabalho e rotatividade na função de frentista. Revista de Administração Contemporânea, v. 5, n. 2, p. 175-200, 2001.

FILIPPIM, E. S.; SANTOS JUNIOR, S.; ZULIAN, L. K.; LAZZAROTTI, F. Motivação e retenção de docentes em instituição de ensino superior comunitária. Reuna, v. 23, n. 1, p. 54-74, 2018.

FLEURY, M. T. L.; FISCHER, R. M. (Coord.). Cultura e poder nas organizações. 2. ed. São Paulo: Atlas, 1996. GIL, A. C. Gestão de Pessoas: enfoque nos papéis profissionais. São Paulo: Atlas, 2007.

GUEST, D. Human resource management and industrial relations. Journal of Management Studies, v. 24, n. 5, p. 503-521, 1987.

LACOMBE, F. J. M. Comportamento organizacional. São Paulo: Saraiva, 2012.

LACOMBE, F. J. M. Recursos humanos: princípios e tendências. São Paulo: Saraiva, 2005.

LEGGE, K. Human resource management. In: ACKROYD, S.; BATT, R.; THOMPSON, P.; TOLBERT, P. S. (Eds.). The Oxford handbook of work and organization. New York: Oxford University Press, p. 220-241, 2006.

LIMA, C. L.; BARRETO, L. M. T. S. Políticas e práticas de gestão de pessoas: um estudo em meios de hospedagem muito confortáveis no Rio Grande do Norte. Revista Hospitalidade, v. 13, n. 1, p. 143-161, 2016.

LIMA FILHO, N. C.; BARBOSA, M. A. C. Gestão por competências e indústria 4.0 em uma empresa alagoana. Cadernos de Gestão e Empreendedorismo, v. 7, n. 2, p. 56-69, 2019.

LIMONGI-FRANÇA, A. C. Comportamento Organizacional: conceito e práticas. São Paulo: Saraiva, 2006.

KNAANE, R. Comportamento humano nas organizações: o homem rumo ao século XXI. 2. ed. São Paulo: Atlas, 1999.

MARANGONI, M. M.; BERIMBAU, M. M. R. Gamificação e gestão de pessoas: um estudo de caso sobre treinamento e ambiente de diversidade cultural. Revista de Carreiras e Pessoas, v. 8, n. 3, p. 431-444, 2018.

MARRAS, J. P. Administração de recursos humanos: do operacional ao estratégico. São Paulo: Saraiva, 2011.

MARRAS, J. P. Administração de remuneração. 2. ed. São Paulo: Pearson Education do Brasil, 2013.

MASCARENHAS, A. O. Gestão estratégica de pessoas: evolução, teoria e crítica. São Paulo: Cengage Learning, 2011.

MOBLEY, W. H. Turnover: causas, consequências e controle. Porto Alegre: Ortiz, 1992.

ORELLANO, V.; MATTOS, E.; PAZELLO, E. A substituição de trabalhadores como instrumentos para redução de gastos com salários: evidências para a indústria paulista. Revista Brasileira de Economia, Rio de Janeiro, v. 63, n. 2, p. 135-152, 2009.

PACHECO, M. S. Evolução da Gestão de Recursos Humanos: um estudo de 21 empresas. 2009. Dissertação (Mestrado em Administração de Organizações) - Faculdade de Economia, Administração e Contabilidade de Ribeirão Preto, Universidade de São Paulo, Ribeirão Preto, 2009. 
PATIAS, T. Z.; WITTMANN, M. L.; LISZBINSKI, B. B.; BALESTRERI, A. S.; COSTA, C. F. Custos da rotatividade de pessoal: evidências no setor de supermercados. RACE: Revista de Administração, Contabilidade e Economia, v. 14, n. 1, p. 143-170, 2015.

PAULA, P.; STEFANO, S. R.; ANDRADE, S. M.; ZAMPIER, M. A. Clima e cultura organizacional em uma organização pública. Gestão \& Regionalidade, v. 27, n. 81, p. 59-73, 2011.

ROBBINS, S. P. Comportamento organizacional. 11. ed. São Paulo: Pearson Prentice Hall, 2005.

SEBRAE, Serviço Brasileiro de Apoio às Micro e Pequenas Empresas. Estudos e pesquisas: perfil dos pequenos negócios. 2019. Disponível em: < https:/ / www.sebrae.com.br / sites/Portal Sebrae/estudos_pesquisas/quem-saoos-pequenos-negociosdestaque5,7f4613074c0a3410Vgn VCM1000003b74010aRCRD>. Acesso em 12 jun. 2019.

SCHEIN, E. H. Foreword: career research: some personal perspectives. In: GUNZ, H.; PEIPERL, M. (Orgs.) Handbook of career studies. Thousand Oaks: Sage, 2007.

SILVA, J. F. Consultoria interna em gestão de pessoas: a chave para a atuação estratégica da área. Revista do CEPE. n. 46, p. 131-148, 2017.

SILVA, L. F. A.; SCHEFFER, A. B. B. A gestão de pessoas nas micro e pequenas empresas: comparando experiências. REGEPE - Revista de Empreendedorismo e Gestão de Pequenas Empresas, v .4, n. 3, p. 87115, 2015.

SILVA, S. W.; FONSECA, L. R.; SILVA, M. R.; PORTUGAL JÚNIOR, P. S.; PIURCOSKY, F. P. Impactos do e-learning em um programa de educação corporativa. Gestão \& Conexões - Management and Connections Journal, v. 7, n. 2, p. 184-202, 2018.

SILVEIRA, V. N. S. Alinhamento estratégico e gestão estratégica de pessoas: análise conceitual e perspectivas teóricas. Revista Pretexto, v. 15, n. 4, p. 114-133, 2014.

SIQUEIRA, M. M. M. (Org.). Medidas do comportamento organizacional: ferramentas de diagnóstico e de gestão. Porto Alegre: Artmed, 2008.

SOUZA, D. A.; PAIXÃO, C. R.; SOUZA, E. A. Benefícios e dificuldades encontradas no processo de seleção de pessoas: uma análise do modelo de seleção por competências sob a ótica de profissionais da área de gestão de pessoas. Gestão \& Regionalidade, v. 27, n. 80, p. 45-58, 2011.

STOREY, J. New perspectives in human resource management. London: Routledge, 1995.

VANALLE, R. M.; SANTOS, E. T. T.; SANTOS, L. B. Práticas de gestão de pessoas: um estudo de casos múltiplos em empresas de bens de capital. Exacta (Online), v. 9, p. 179-196, 2011.

VERGARA, S. C. Gestão de Pessoas. 4. ed. São Paulo: Atlas, 1999.

VIEIRA, M. A.; SILVA JÚNIOR, A. da; SILVA, P. de O. M. da. Influências das políticas e práticas de gestão de pessoas na institucionalização da cultura de segurança. Prodution, São Paulo, v. 24, n. 1, p. 200-211, 2014.

WAGNER III, J. A.; HOLLENBECK, J. R. Comportamento organizacional: criando vantagem competitiva. Tradução de Cid Knipel Moreira. São Paulo: Saraiva, 2003.

WOOD JR., T.; TONELLI, M. J.; COOKE, B. Colonização e neocolonização da gestão de recursos humanos no Brasil (1950-2010). Revista de Administração de Empresas, v. 51, n. 3, p. 232-243, 2011.

YIN, R. K. Estudo de caso: planejamento e métodos. Tradução de Cristhian Matheus Herrera. 5. ed. Porto Alegre: Bookman, 2015. 